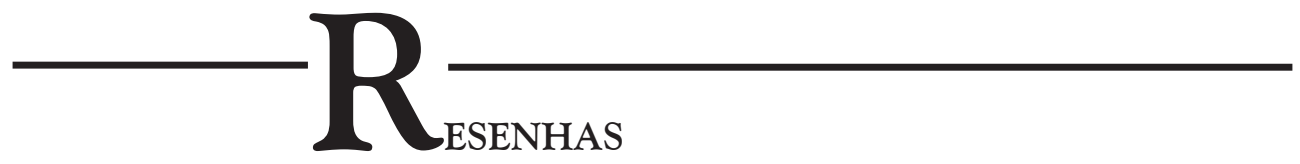

SARRÍA, Leonardo. La palabra y la llama: poesía cubana de tema religioso em la Colonia. La Habana: Editorial UH, 2012. 144 pp.

\title{
UMA CARTOGRAFIA ABERTA: A TEMÁtICA RELIGIOSA NA POESIA CUBANA
}

\section{Anaxsuell Fernando Silva Universidade Federal da Integração Latino-Americana (UNILA)}

Seria possível traçar um mapa, uma rota, do corpus poético cubano a partir das "temáticas religiosas"? Esta pergunta foi o mote de Leonardo Sarría, autor de La palabra y la llama: poesía cubana de tema religioso em la Colonia. Parte da crítica literária e da historiografia latino-americana tem optado por estabelecer nominações monolíticas, tais como "poesia sacra", "poesia religiosa", "devota", "ascética", "mística", "patriótica", entre outras. No uso destes apêndices nominativos, esquece-se das apropriações, dos usos retóricos, cruzamentos e hibridações. Deixa-se de compreender a literatura - neste caso, a poesia - enquanto campo de possibilidades e se subdimensiona seu caráter plurívoco e aberto.

O período colonial é, de acordo com Sarría, aquele com maior carência de apreciações críticas (p. 16), embora esta época seja responsável pelo engendramento de um conjunto de ideias, atitudes e imaginários medulares na formação identitária cubana. Motivado por este vácuo na crítica literária, o autor inicia seu percurso investigativo ainda em 2008 com a publicação de seu primeiro livro: Golpes de agua. 
Antología de poesia cubana de tema religioso. Uma compilação de poesias com tema religioso, com a finalidade de apresentar um "universo vasto, complexo, plural" (: 17) das expressões religiosas insulares. Posteriormente, esta publicação serviria de corpus analítico para sua tese de doutorado em Ciências Literárias, defendida em 2011 na Universidad de La Habana, mesma instituição em que se tornou professor.

O contexto histórico-religioso caribenho foi marcado pela larga influência do cristianismo - mais concretamente, do catolicismo. Logo, a produção poética colonial de Cuba traz consigo claras correspondências com esta cosmovisão religiosa. Apenas na segunda metade do século XIX expressões poéticas relacionadas a outras expressões de práticas religiosas (notadamente panteísmo e espiritualismos) viriam à tona.

O livro em questão é composto por sete seções ensaístico-expositivas, em substituição aos tradicionais capítulos. Com estilo particular, Leonardo Sarría desenvolve seus argumentos na medida em que considera a crítica literária como experiência igualmente criadora e poética. Entusiasmado com o livro, seu prefaciador, o premiadíssimo escritor e crítico cubano Roberto Fernandez Retamar afirmou: "vale esperar de Sarría una continuación de su libro que aborde la poesía cubana posterior a la Colonia" (p. 10).

No primeiro ensaio, chamado de Primeras manifestaciones. Ejercicios retóricos. Pruebas y castigos de lo alto, o autor aponta que boa parte da produção cubana durante o período colonial é devota, de interesse catequético-católico. Nesta direção, ele atribui maior destaque àquela que seria a primeira produção literária originada na Ilha: Espejo de Paciencia, escrita por Silvestre de Balboa Troya de Quesada por volta de 1608. Trata-se de um poema épico-histórico que narra em oitavas o sequestro do bispo cubano Fray Juan de las Cabezas Altamirano pelo pirata Gilberto Girón. Este relato de celebração de vitória - segundo a historiografia cubana - serviu de cântico na igreja de Bayamo e tracejava linhas distintivas entre as qualidades morais-religiosas dos nativos criollos em contraste com a violência gratuita dos "outros". Sarría ressalta pormenorizadamente a construção das personagens, o enredo e a métrica desta obra literária em que uma figura católica (bispo), um herege (o corsário), divindades pagãs, fauna e flora se entremeiam na ausência de um formalismo religioso.

A sensação de dependência existencial e desvalimento ante as dominações estrangeiras possibilitou a eclosão de uma lírica de exortação e súplica: "casi como una oración religiosa" (: 28). De acordo com o autor, os paralelos entre a ocupação inglesa de La Habana e a trajetória de sofrimento do povo de Israel despertaram ânsias libertárias, as quais serviriam de base a poemas independentistas. Neste aspecto, Pedro Santacilia y Palacios, Joaquín Lorenzo Luaces e Justiz de Santa Ana recebem destaque. Outro desdobramento desta sensação de dependência existencial está nos poemas de Álvarez de Miranda, os quais atribuem às catástrofes naturais ocorridas na Ilha uma causalidade moral. Nas palavras de Sarría, tais poemas enumeravam "las capitales arrasadas em la Biblia por la ira de Dios, unido a la patética descripción de los estragos de la tormenta y al recordatorio del terremoto de Santiago de Cuba" (: 29). 
No ensaio seguinte, El anónimo miserere en sonetos. Despunte de las reescrituras bíblicas, Sarría parte de um conjunto de sonetos, anônimo, chamados miserere. Refere-se a uma valoração extremada da disciplina eclesial, das qualidades subjacentes à oração individual e, principalmente, marcados por uma escassez subjetiva. $\mathrm{O}$ autor traz ao longo deste ensaio alguns exemplos de poetas que reescreviam textos bíblicos - destaca Dios y el hombre, de Rafael de Cárdenas, e Dios y la criación, escrito por Diego Vicente Tejera - ou aproveitavam as lacunas existentes nas narrativas bíblicas para inspiração temática, como Manuel Justo Rubacalva fizera em La muerte de Judas.

Em El Dios del torrente. Heredia como creador del cielo civico. Estampas de la cruz. Placido y Milané, o crítico literário discute que foi apenas após o romantismo que Deus apareceu na literatura cubana como "espirito de vida", descrito como abrasadoramente sublime e um rapto de iluminação. Para tais descrições da manifestação divina na poética cubana, Sarría utiliza o conceito de numinoso, cunhado por Rudolf Otto. Esse conceito permitiria perceber que as representações em torno da ideia de "mysterium tremendum, majestas, fascinans y energicum" (: 43) substituíram as expressões poéticas institucionais, racionalizadas, litúrgicas, convencionais apontando para o contato com a experiência numinosa.

Dito de outro modo, a manifestação divina na poética cubana abandonou seu lastro doutrinário, épico, teatral e catequético com o qual havia aberto o século XX. E, desta feita, assenta-se, de acordo com Sarría, numa sensibilidade mais impactante e mais sofisticada em seus aportes filosóficos.

Nenhuma das vozes do século XIX da Ilha conta com uma obra poética de expressão religiosa de solidez, pluralidade e força como a de Gertrudis Gomez de Avellaneda. Por isto, Leonardo Sarría dedica um dos ensaios do seu livro a esta autora - El sentimiento de criatura. Esta sessão descreve trinta poemas, nos quais figuram reescritas bíblicas - paráfrases, traduções e mímeses - músicas religiosas e textos de incerta classificação. Nosso autor considera que "en manos de Avellaneda la traducción o la simple paráfrasis versicular tienden a transformarse em substancia u oración propias" (: 61). Mais adiante, ao falar do erotismo presente nos versos de Avellaneda, o crítico em questão afirma que ela era uma audácia para o seu tempo.

No ensaio posterior, La virgen criolla de El Cucalambé. Lirica revolucionaria y tema religioso. Las reescrituras de Santacilia y luaces, o autor trata da epopeia libertadora contra o poderio espanhol expressa nas poesias. Particularmente nas inúmeras referências aos mártires cristãos, ressaltam-se a integridade patriótica ante a opressão do regime e a necessidade de superá-lo (tal qual o fizeram os Hebreus). Destacam-se Antonio Maceo e Joaquín Lorenzo Luaces.

Na sexta sessão do livro, o ensaio Mayor intimidad del acento. La emoción elegíaca. Mendive, Zenea, Luisa Pérez de Zambrana será dedicado a uma nova forma de representação divina que emerge na lírica cubana. Entre os poetas da segunda geração do romantismo, Leonardo Sarría identifica o fascínio destes com as grandes manifestações da natureza, sejam montanhas, paisagens crepusculares ou noturnas 
que permitem uma maior introspecção. Como exemplar deste momento, somos apresentados a Rafael María de Mendive. Em seus poemas percebe-se um Deus dissolvido em toda natureza, pluriforme. A iminência da morte permite questionar os dogmas basilares do cristianismo e evidenciar um forte sentimento de vazio existencial. Sarría conclui este ensaio enfatizando Luisa Pérez de Zambrana e as suas queixas rebeldes pelas quais "hasta em su etapa de más visceral desgarramiento mantendría una extraordinaria tenacidad".

No último ensaio do livro Orientaciones y referentes outros, Sarría inicia mencionando Flores del espiritismo, uma coletânea de poesias para fins de proselitismo. Estas teriam sido ditadas a uma médium bastante conhecida na Ilha. Sarría salienta sua "insignificância estética". Contudo, sua importância estaria no fato de trazer outras referências religiosas para uma lírica predominantemente de identificação católica. Semelhantemente, na medida em que a poética modernista se desenvolve, outras referências religiosas na poesia emergem, como, por exemplo, ocultismo, satanismo e misticismo não circunscrito a nenhum corpus confessional.

Permeadas pelo racionalismo positivista e uma ascendente secularização que removia e ressignificava os limites do sagrado, Jose Martí, em seus Versos Sensillos (1891), com delicada melancolia se aparta da fidelidade poética ao cristianismo e caminha para uma "religión natural" (: 105). E, assim, parece se aproximar do panteísmo ao considerar que a divindade é todo o universo. Os poemas martinianos são de substância messiânica, mística e forjaram ideais de revolução deste crítico de "una iglesia reaccionaria, traidora de su auténtico mensage y ministerio" (: 115). Neste misticismo revolucionário, a pátria é o numinoso.

Mais que compendiar um significativo número de autores e autoras nativas da Ilha, evidenciar poemas destes e nos colocar a par das apreciações críticas, Sarría tem o mérito de nos conceder uma cartografia da religiosidade cubana. Não foi por acaso que sua tese de doutorado - aqui em formato de livro - foi premiada pela Comisión Nacional de Grados Cientificos em 2011. Trata-se de um trabalho de qualidade, que merece ser lido.

\section{Referências Bibliográficas}

MARTÍ, José. ([1891] 2001), Versos Sensillos. Habana: Centro de Estudios Martianos.

SARRÍA, Leonardo. (2008), Golpes de agua. Antologia de poesia cubana de tema religioso. Habana: Editorial Letras Cubanas.

Anaxsuell Fernando Silva (anaxsuell.silva@unila.edu.br) Doutor em Ciências Sociais pela Universidade Estadual de Campinas (Unicamp). É professor de Antropologia na Universidade Federal da Integração Latino-Americana. 